\title{
Eighteen Months of Meeple Like Us: An Exploration into the State of Board Game Accessibility
}

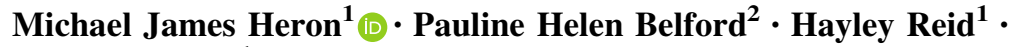 \\ Michael Crabb ${ }^{1}$
}

Received: 18 January 2018/Accepted: 15 April 2018/Published online: 21 April 2018

(C) The Author(s) 2018

\begin{abstract}
The study of game accessibility to date has largely focused on the topic of accessibility within a video game context. Largely underexplored in the academic and professional literature is accessibility in the domain of tabletop games, especially those that are classified as part of the 'hobbyist' market. An ongoing series of research annotations, published on the blog Meeple Like Us, has been aimed at addressing this lack of attention. In this paper, the authors report on the work of the Meeple Centred Design project which to date has examined 116 board games for the accessibility issues they manifest and the lessons that can be learned for designers in this space. While the project has not achieved significant coverage of even a fraction of the available library of hobbyist games, currently numbering approximately one hundred thousand, it has discussed the issues with many of the most critically success and popular of these titles. This paper reports on results to date, methodology of the analyses, limitations of the project, and the future plans for work in this interesting game accessibility context.
\end{abstract}

Keywords Board games · Accessibility · Inclusion · Tabletop · Meeple like us · Universal access

Michael James Heron

m.j.heron1@rgu.ac.uk

Pauline Helen Belford

p.belford@dundeeandangus.ac.uk

Hayley Reid

1300777@rgu.ac.uk

Michael Crabb

m.j.crabb@rgu.ac.uk

1 Robert Gordon University, Aberdeen AB10 7QB, Scotland, UK

2 Dundee and Angus College, Arbroath DD11 3EA, Scotland, UK 


\section{Introduction}

The topic of accessibility in digital products is relatively well discussed in the academic literature. There are high impact conferences focused on exploring the relationship between humans and computers. Often these discussions include a considerable amount of focus on how computer interfaces present themselves to users with disabilities and other interaction concerns. Relatively recently, this topic has expanded to include discussions of the accessibility of video games (Heron 2012; Porter and Kientz 2013) and how they can be made more playable by a wider audience of people. Similarly, there is a vibrant academic discourse that takes places around the topic of accessibility in physical environments. This includes areas of real world impact such as transport (Rode et al. 2017), health (Kwan 2013), and access to buildings (Karimi et al. 2014). It also includes manifestations of play in the form of accessible sports (McCormick et al. 2013). Accessibility is a topic that is often at the forefront of public and academic discourse.

Relatively unexplored in any context though is the topic of physical game accessibility, best represented by board games, card games, miniatures games and other tabletop recreational experiences. The popularity of these titles has been increasing at a considerable pace in recent years ${ }^{1}$ with the hobbyist tabletop game market now surpassing a billion-dollar market cap. ${ }^{2}$ Sales are growing at the rate of approximately $30 \%$ a year in Europe and attendance at tabletop hobbyist conventions is increasing at a pace that often outstrips the ability of organisers to adapt. This is now a rich, popular, and exciting area of recreation that has received virtually no serious attention as far as accessibility is concerned. In this paper, we report on the first eighteen months of the Meeple Like Us project which is aimed at addressing this deficiency in the literature.

\section{Background}

The issue of accessibility in board games has received almost no serious academic and industry attention to date. There is no academic ecosystem devoted to the modern board-game industry and few popular periodicals. Where board games are discussed in the academic literature it is primarily as a byproduct of other research goals. They have been used to train artificial intelligences (Szita et al. 2009; Taylor 2014); adopted for therapeutic benefits in play therapy (Matorin and McNamara 1996; Gotay 2013); explored for the historical and archaeological insights they provide Crist et al. 2016; Hall 2016) and used as test cases for issues of game theory (Guhe and Lascarides 2014). There are numerous academic papers that explore board-games for their own intrinsic benefits (c.f. Barbara 2017; Bremer 2017; Rogerson et al. 2016) but these are vanishingly rare in the wider academic literature. The topic of board-game usability is an almost unexplored topic and the background

\footnotetext{
${ }^{1}$ https://www.businesswire.com/news/home/20170310005645/en/Global-Board-Games-Market-GrowCAGR-29.15.

2 https://icv2.com/articles/news/view/38012/hobby-games-market-over-1-4-billion.
} 
literature of this paper is forced to reflect that fact. Only (Noble and Crabb 2016) serves as a relevant paper of note here, and even that is one that is linked to one of the co-authors of this paper and informed by earlier work of the Meeple Like Us project outlined in this paper.

The study of tabletop board game accessibility introduces nuances and subtleties that need careful consideration and addressing. Accessibility in digital environments is largely funded by an upfront cost that generates additional funding through expanding an audience share. There are per-unit and logistical issues associated with changing the accessibility of a physical product. Even simply testing games with disabled gamers is beyond the scope of most publishers, as is evidenced by the fact that even the comparatively simple compensations required for colour blind support are often ignored. And yet, there are many easy accessibility improvements that can be made with only minimal cost. Disability and accessibility interact in many nuanced and complex ways, and impairment in one category of interaction need not render a game inaccessible in others. The difference between broadly inaccessible and broadly accessible may be as simple as a font change or an alteration in the physical tactility of tokens.

For the past eighteen months, the primary author of this paper has been working on the Meeple Centered design project, which reports directly to the hobbyist community through the Meeple Like Us website and blog (http://meeplelikeus.co. uk). The website does game reviews and accessibility analyses of popular hobbyist games, recommending them in a variety of categories of accessibility. Each recommendation is accompanied by an extensive discussion of the reasons for the grade it was awarded. This work to date has been, like the board game industry itself, entirely hobbyist and driven by personal enthusiasm. Meeple Like Us has been noted in outlets as varied as the Guardian and Geek and Sundry, bridging both the mainstream media and enthusiast blogs.

The work of this project has shown that board-gaming is certainly a feasible hobby for people with disabilities of all kinds. The games as delivered though often fail to take into account accessible design because it simply isn't a topic with which the industry can meaningfully engage. The diversity and nuance of board game interaction is tremendously large-games which seem to be functionality identical may differ strikingly in their accessibility. Games with the simplest rules may be cognitively inaccessible when more complicated games can be house-ruled to be completely playable. Within video gaming, there is a limited set of peripherals that act as an interface to a game. A single board-game may incorporate cardboard chits, plastic tokens, wooden meeples, cards, and a small mountain of dice. Another game might have dozens of plastic miniatures and a huge, modular board that expands with exploration. Another still might involve the rapid flipping and collection of tiles against a time limit, and the placing of those tiles according to set placement rules on an individual player board. Others might involve nothing more than plastic cups, auctioneer paddles, and a rapidly delivered countdown. Assessing the accessibility implications of any given combination of rules, components and aesthetics is a deeply specialised task that requires skill-sets and experience not generally available in bulk to publishers. 
Accessibility in video games is different from accessibility in other digital realms because the exact nature of interaction is often as critical for building immersion as any on-screen activity. This represents a difference in kind rather than scale, and this in turn requires a very complex understanding of both the vocabulary of game design and the specialist toolkit of accessibility. With board games, we have this same issue but layer in a large number of additional complications including the specific nuance of components and the need to maximise benefit at the minimum of per-unit cost. As such, accessibility guidance given for one game may not actually be feasible or sensible for another. The use-case of a six-sided die in one game likely will not be the same as in another. For some games they are randomisers, for others they are units that represent varying numeric game state. Contrary to the way in which most software converges towards a set of reasonably well agreed upon conventions, games thrive in part through their originality of interaction and their distinctiveness (Katzenbach et al. 2016). Similarly, the physicality of a board game permits it to draw across all sensory categories. There are games that stress the sense of vision, or hearing, or communication. There are games that incorporate smells or touch. There are games that focus on the more intangible senses associated with social context. Accessibility guidance in this area must be deeply informed by the experience of individual play, and this is a context in which even accessibility practitioners are likely to have little substantive experience. The knowledge base needed to meaningfully address interaction in an analog gaming environment is very different from that needed for video games.

Further complicating this is the fact that physical, visual and cognitive impairments may interact in non-obvious ways. A standard example is that certain cognitive impairments make it difficult to interpret synthesized speech (Pullin and Newell 2007) which makes one possible compensation for blindness ineffective for those who may also have cognitive impairments. The gaming market, like the general population in which it exists, is growing older. For older players the issue can be further complicated by the fact that aging brings with it a complex suite of minor ailments (Newell and Gregor 2000) none of which may be significant enough on its own to be self-described as an impairment (Gregor et al. 2002). As such, a fix for one issue might introduce problems for another and players may not even be aware that accessibility support is relevant to them.

Even without these additional, highly contextual interaction issues there are problems in communicating accessibility 'best practise' to non-specialists. Guidelines as a tool for informing development have issues when they are interpreted without respect for the nuance (Milne et al. 2005). Nuance is the most critical element that comes with developing generalised accessibility guidance in this area. The current state of the industry, and the current state of accessibility research, are not currently geared around providing useful insight in this highly specific context. Work within the Meeple Centred Design project is aimed at providing illumination in this regard.

In this paper, the authors reflect on the Meeple Like Us project (http:// meeplelikeus.co.uk) and the findings to date of a year and a half's exploration of the tabletop accessibility landscape. Meeple Like Us is a series of research annotations and reflections on the accessibility profiles of many popular hobbyist board-games. 
Each game is given a full write-up with review and accessibility analysis, and this pair of posts is published on a weekly basis on a public-facing blog for all to see and comment. To date the Meeple Like Us project has analysed 116 games, although not all of these have yet been published to the blog. The blog has had some 120,000 visitors over the course of its existence and has provoked a large degree of comment and commentary online through Twitter, Facebook, Reddit and other hobbyist outlets. The work has been controversial in many respects, largely because of the attention paid to issues of representation and diversity. However, the work has also been valuable to many hobbyist gamers who have appreciated the detail of the teardowns and the often nuanced consideration of individual and intersecting accessibility concerns. The Meeple Like Us project is ongoing, expanding in scope, and the results of the first eighteen months are presented here as an early progress report for interested parties.

\section{Project Scope}

Given the number of games that are released on a monthly basis, it is impossible for the Meeple Like Us project to cover even an appreciable fraction of new releases. Over 5000 new tabletop games were registered with the hobbyist database BoardgameGeek (BGG) in 2016, and the scale of the task of fully assessing a game for its accessibility is time consuming. It requires multiple play sessions with the game, a consideration of the game from various angles of accessibility, and the write up of an extensive document that provides justifications for all conclusions reached. As such, the goal of the project has been to cover a non-trivial percentage of the Top 500 games as outlined on BGG. This is an autogenerated list derived from the aggregated ratings from thousands of users, each of whom attaches a rating from one to ten to games with which they have experience. It is also a listing where a certain degree of fudging and Bayesian averaging is applied to ratings so as to minimise the distortion caused by games with a small number of very high ratings. From the $\mathrm{FAQ}^{3}$ :

BGG Rating (aka Geek Rating): BoardGameGeek's ranking charts are ordered using the BGG Rating, which is based on the Average Rating, but with some alterations. To prevent games with relatively few votes climbing to the top of the BGG Ranks, artificial "dummy" votes are added to the User Ratings. These votes are currently thought to be 100 votes equal to the mid range of the voting scale: 5.5 , but the actual algorithm is kept secret to avoid manipulation. The effect of adding these dummy votes is to pull BGG Ratings toward the mid range. Games with a large number of votes will see their BGG Rating alter very little from their Average Rating, but games with relatively few user ratings will see their BGG Rating move considerably toward 5.5. This is known as "Bayesian averaging" and a quick search of both BGG and/or the Web will reveal much discussion on the topic.

\footnotetext{
${ }^{3}$ https://boardgamegeek.com/wiki/page/BoardGameGeek_FAQ.
} 
There is little curation of the BGG top rankings - a single game may appear several times in different editions, and other games may have passed into obscurity as their publishers went out of business, lost publication rights, or simply withdrew the product from market.

This is not a list that is particularly meaningful in a real, quantifiable way, It doesn't represent anything other than the views, filtered through a mysterious algorithm, of those that frequent the site. However, it represents a reasonable proxy for some degree of significance within the hobby, and it is under that basis that the list is used. It is not though used exclusively_-games outside the Top 500 are also covered as they are played by Meeple Like Us project participants. Occasionally requests are made for games to be covered, and when it is possible these will be added to the list of candidate games. Coverage of games too is dependent on availability_given the age of the BGG rankings, many entries are no longer available or have been superseded by other games or editions. Where games are not available, they cannot be covered. When a new edition of a game is released, or is announced, it also means that older editions of games that are available cease to be relevant to discussion.

Currently, with 116 games covered, the Meeple Like Us project has analysed $16.8 \%$ of the BGG Top 500 and $10.1 \%$ of the top 1000 . Progress made is slow, but steady-approximately $10 \%$ of the BGG Top 500 is covered per year at current rates, and so it can be anticipated that by the fifth year of operation the site will have coverage of approximately half of the games in the database.

\section{Methodology and Limitations}

The specific methodology for assessment varies from game to game-the nuance and subtleties of any individual title introduce complexities that must be addressed on a case by case basis. A heuristic framework of common elements is available (Heron et al. in prep) but this serves as a guideline rather than an exhaustive and consistent analytical tool. The variety of game mechanics mean that occasionally a game might stress a unique combination of factors that would have no place as a generic guideline. Games such as Parfum ${ }^{4}$ make use of the sense of smell through scratch and sniff mechanics. Games such as Bring Your Own Book ${ }^{5}$ require players to produce a book of their own, which moves accessibility issues outside the context of static and standardised game components. Some games have elements that change through play, with Legacy style campaign games becoming increasingly common - the copy of one player in such games may differ significantly from that of another. Each game that is covered on Meeple Like Us is played a minimum of three times in order to arrive at the accessibility recommendations.

Individual analyses are bespoke, but a consistent technique is applied when it comes to analysing games. This is to break down (or teardown, in the context of the jargon of Meeple Like Us) accessibility issues through a set of categorical lenses:

\footnotetext{
${ }^{4}$ https://boardgamegeek.com/boardgame/172546/parfum.

5 https://boardgamegeek.com/boardgame/173441/bring-your-own-book.
} 


\begin{tabular}{|c|c|}
\hline Lens & Description \\
\hline Colour blindness & $\begin{array}{l}\text { Relating to issues where colour is used as the sole channel of information for } \\
\text { game state, and how the palette chosen works for that }\end{array}$ \\
\hline Visual accessibility & $\begin{array}{l}\text { Relating to issues of visual impairment, primarily where there is some degree of } \\
\text { ability to differentiate visual information. Total blindness is considered in } \\
\text { these sections, but it is not the primary focus. Later work for the project is } \\
\text { planned to address this }\end{array}$ \\
\hline Physical accessibility & $\begin{array}{l}\text { Relating to issues of fine-grained or gross motor control. Issues here include } \\
\text { elements of dexterity, precision, and the extent to which a game facilitates play } \\
\text { with verbal instruction }\end{array}$ \\
\hline $\begin{array}{l}\text { Cognitive } \\
\text { accessibility }\end{array}$ & $\begin{array}{l}\text { Relating to issues of fluid intelligence and crystalised intelligence (Cattell 1963). } \\
\text { Game complexity is an issue here, but it is not necessarily a predictor of the } \\
\text { accessibility of the game in the end. Even very simple games may be } \\
\text { cognitively inaccessible. Also included in this category are issues of expected } \\
\text { literacy as well as implicit and explicit numeracy }\end{array}$ \\
\hline $\begin{array}{l}\text { Emotional } \\
\text { accessibility }\end{array}$ & $\begin{array}{l}\text { Related to issues of anger and despair, and how they might manifest through } \\
\text { score disparities, bullying through game mechanisms, and the extent to which } \\
\text { the game requires players to deal with stress or upset }\end{array}$ \\
\hline $\begin{array}{l}\text { Communication } \\
\text { accessibility }\end{array}$ & $\begin{array}{l}\text { Related to issues of articulation and perception of communication. Literacy is } \\
\text { discussed here too as are the patterns of communication. In this section we } \\
\text { work on the assumption that a group of players has some means by which they } \\
\text { can communicate in day to day life, so we address only those elements specific } \\
\text { to the game itself }\end{array}$ \\
\hline $\begin{array}{l}\text { Socioeconomic } \\
\text { accessibility }\end{array}$ & $\begin{array}{l}\text { Related to issues of representation, diversity, and inclusion. Heron (2016) } \\
\text { outlines these as issues of an accessibility of perception. Also covered in this } \\
\text { section are costs and business models including when games have collectible } \\
\text { elements or whether they work on the assumption of expansion }\end{array}$ \\
\hline $\begin{array}{l}\text { Intersectional } \\
\text { accessibility }\end{array}$ & $\begin{array}{l}\text { Related to the accessibility issues that might arise particularly through the } \\
\text { intersection of other categories above }\end{array}$ \\
\hline
\end{tabular}

Each game receives a full discussion of issues relevant to each category, and a recommendation is given in standard alphabetic grading. These correspond to the following:

\begin{tabular}{|c|c|c|}
\hline Grade & $\begin{array}{l}\text { Numerical } \\
\text { value }\end{array}$ & Meaning \\
\hline A & 14 & $\begin{array}{l}\text { Strongly recommended-suitable for anyone with accessibility concerns in this } \\
\text { category }\end{array}$ \\
\hline B & 11 & $\begin{array}{l}\text { Recommended-likely suitable for anyone with accessibility concerns in this } \\
\text { category, but there may be some small issues that need resolved }\end{array}$ \\
\hline $\mathrm{C}$ & 8 & $\begin{array}{l}\text { Tentatively recommended-can likely be made playable although there are } \\
\text { substantive concerns in particular cases }\end{array}$ \\
\hline D & 5 & $\begin{array}{l}\text { Not recommended—can possibly be made playable but only with extensive } \\
\text { modifications or impact on game enjoyment }\end{array}$ \\
\hline E & 3 & $\begin{array}{l}\text { Strongly not recommended-it is unlikely this game will be enjoyable by anyone } \\
\text { impacted by issues in this category }\end{array}$ \\
\hline F & 0 & $\begin{array}{l}\text { Stay away-it is believed this game is fundamentally incompatible with issues } \\
\text { that emerge in this category }\end{array}$ \\
\hline
\end{tabular}


Numerical values are used to calculate averages and standard deviations, and standard plus and minus modifiers are used within each letter grade to provide a small degree of nuance. For the purposes of analysis, these have all been collapsed into the descriptive grades used in the charts presented below. These grades are then summarised in a radar chart that goes along with each document. While radar charts are a problematic mechanism for presenting complex data (Few 2005), they give the benefit of a quick way for someone to associate patterns of interaction with their own personal requirements. An example of such a radar chart for the game Tiny Epic Galaxies ${ }^{6}$ ) is given in Fig. 1.

It is important to note here though that this work has several significant limitations, and the results as outlined must be assessed in that regard. The first is that of a necessity these recommendations are derived from a relatively abled perspective. They do not therefore carry the weight of authenticity that would be associated with an embodied appreciation of accessibility issues (Imrie 2004). This is a fundamental limitation of this model of analysis-more accurate recommendations in each category would require a player with representative accessibility concerns to have played a game that may not be at all playable, and have done that often enough to be able to fairly interpret the game mechanics accurately and consistently. The time requirements, and the logistical difficulties involved, prohibit this approach for the Meeple Like Us project. Approaches that would offer more embodied calibration of recommendations are under active consideration. To compensate for this, viewpoints from external parties are solicited openly through blog comments and social media. Where individuals can offer a real-world perspective to adjust these recommendations, these are folded in where appropriate. All impacted documents include a change log to note where this has happened.

Similarly, the majority of these teardowns are written from the perspective of a cisgendered male of relatively privileged socioeconomic standing. Other viewpoints on issues of inclusion and representation are encouraged and solicited, and where they are provided they are used to adjust recommendations upwards or downwards as necessary.

Letter grades then do not represent a quantified or validated data point-instead they represent a subjective, qualitative judgement on games. All teardowns are either conducted or reviewed by a research-active academic working in the field of game accessibility (c.f. Heron et al. 2013a, b; Heron 2015) so while these recommendation grades are not necessarily accurate they are derived from informed analysis. They should not be taken as being correct, but the full thinking behind each letter grade is provided so interested parties can draw their own conclusions regarding the suitability of games in particular categories.

Similarly, the collapsing of complex accessibility issues into a single letter grade is never likely to be a satisfying process. Visual impairments alone include situational impairments brought upon by environmental concerns (Newell et al. 2011) to more persistent issues of cataracts, glaucoma and astigmatism. They may be temporary and minor, or permanent and severe. With all of that in mind, all a single letter grade can do is identify what is perceived to be profitable territory for

\footnotetext{
$\overline{6}$ https://boardgamegeek.com/boardgame/163967/tiny-epic-galaxies.
} 


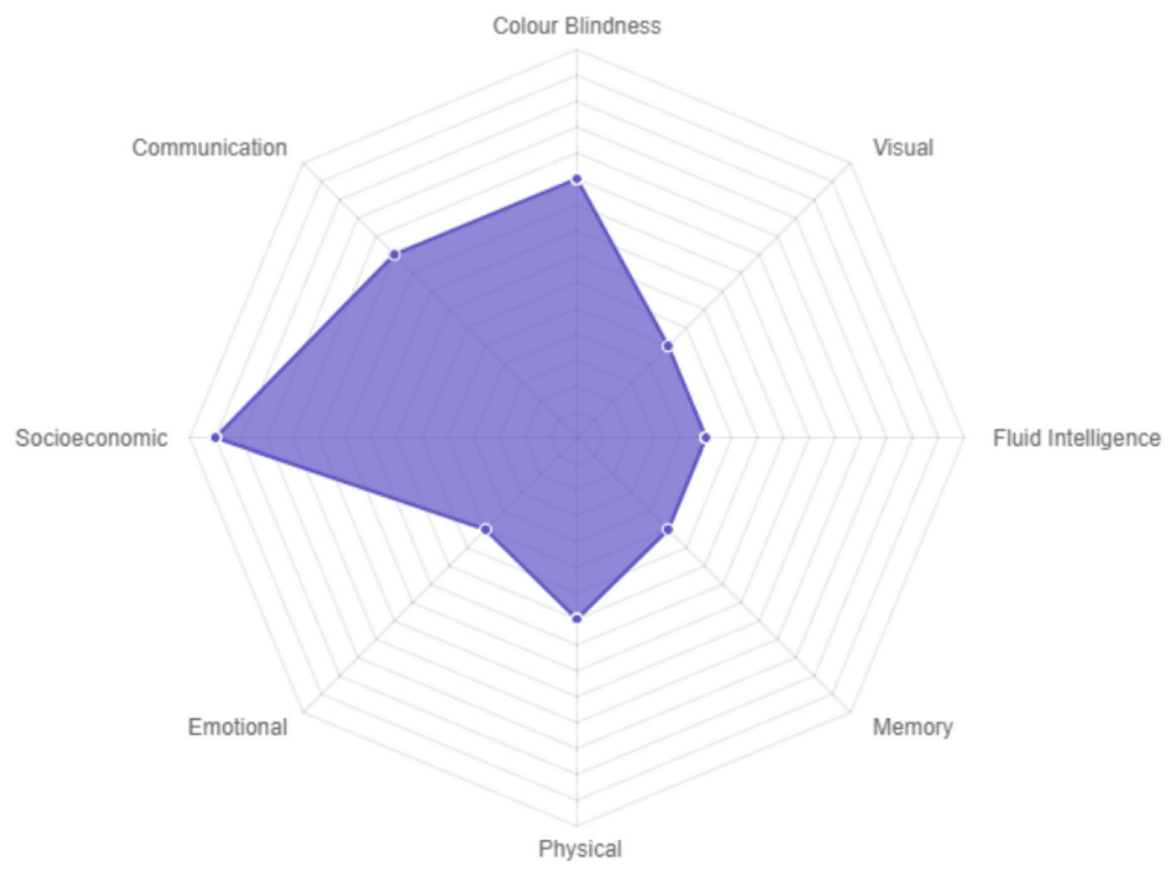

Fig. 1 Accessibility radar chart for tiny epic galaxies, available at http://MEEPLELIKEUS.CO.UK/ TINY-EPIC-GALAXIES-2015-ACCESSIBILITY-TEARDOWN/

those examining games for suitability. They represent points of interest that have been mapped in the accessibility landscape. However, they also suffer many of the same issues that plagued early real world cartographical efforts. Occasionally a hazard that sinks a boat is missed, or an explorer marks 'here be dragons' to indicate danger where none is to be found. The limitations of this work are reflected all the way through the site to ensure that conclusions drawn by readers bear no more credibility than can be reasonably assumed.

\section{Results and Discussion}

A full list of games covered on Meeple Like Us, and the associated accessibility grades, can be found at http://tinyurl.com/meeplelikeus. A secondary internal spreadsheet is used to provide data on titles not yet published on the blog-it is the latter of these that is used to generate the information in this paper. Interested parties can contact the primary author for a copy of the live data. All teardowns are provided on a CC-BY 4.0 basis, and this is indicated on each document. In this section we will discuss the findings in the abstract, with few references to specific games. Grades for each category are awarded based on the average of all accumulated recommendations. For all categories, $\mathrm{N}=116$. 


\subsection{Colour Blindness}

Colour Blindness, according to the rating and numerical weightings outlined above, averages out at a B grade. Numerically this comes out as a 10.92 average with a standard deviation of 3.30 .

By and large colour blindness is a persistent, ongoing issue in board games although it is rarely one that fully prohibits players from engaging in a game experience. Primarily the issues arise in token discrimination where sub-optimal palettes are used to indicate player ownership and control of elements of board state. However, some games also adopt a large amount of colour-based pattern identification and manipulation and these often present a considerable barrier to play. Even in these cases the problems are usually, but not always, situational. Colour blindness is an issue that can be resolved in many cases by board alterations-painting or marking game components so as to ease identification. However, these kind of modifications are outside the scope of the project since it is not the view of the authors that players should be expected to deface their games in order to get a fully playable experience.

More substantial problems exist when relating components to other parts of the game state, such as when colours are used as the sole indicator of category on cards and in manuals. In such cases, even modifying the game is not an appropriate solution to problems encountered.

In many cases, colour blindness problems manifest only for certain categories of colour blindness, and even then often only at the highest supported player counts. In other cases, the number of game components used is small enough that external components can be substituted to track whatever game state the component itself was used for. Figure 2 shows the distribution of recommendations in this category.

There remain some games that present many insoluble accessibility challenges in this category, but by and large colour blindness is a persistent consideration rather than a critical barrier to play.

\subsection{Visual Accessibility}

Visual accessibility, according to the rating and numerical weightings outlined above, averages out at a C-grade. Numerically this comes out as a 7.05 average with a standard deviation of 3.41 .

The grade for visual accessibility is artificially skewed upwards because the recommendation conflates games which work for people with visual impairments and yet don't work for people with total blindness. Later revisions of the work in the second phases of this project are intended to address this to give a more balanced and nuanced view of the category. With that in mind, while the averaged grade is just within the bounds of being tentatively recommended the true state of affairs is that this is not an accurate reflection of the work to date. Future analysis in later papers will correct this deficiency in the analysis.

Even for those with visual impairments this is a hobby that can only be recommended in specific cases and often when dealing with only relatively minor visual impairments. Within this section we work on the assumption that game state 


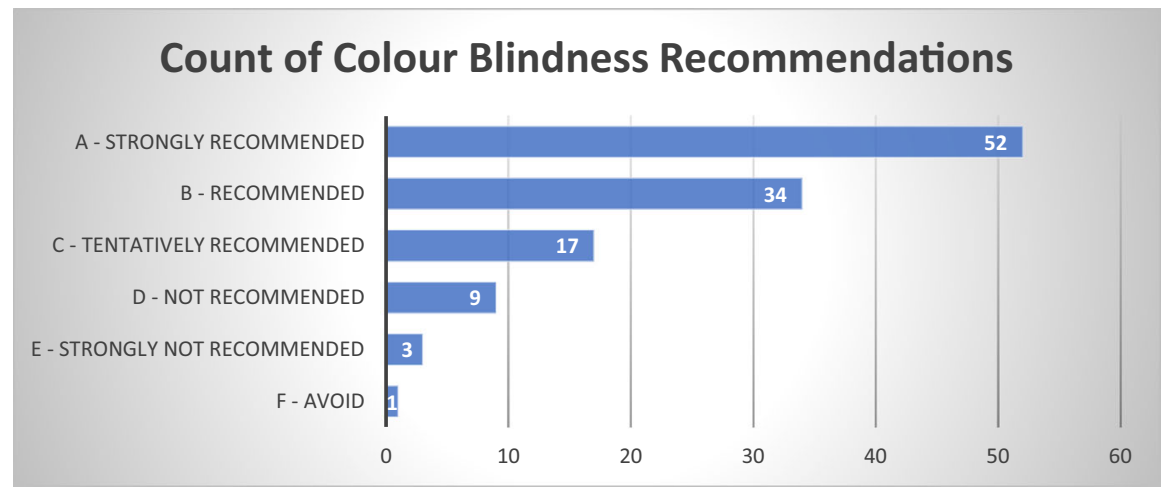

Fig. 2 Recommendation grades for colour blindness

can be assessed through the use of an appropriate assistive aid. Figure 3 shows the count of recommendations for this category of accessibility.

Many games require a large amount of 'table knowledge' from each player-it's important that players know what parts of the game are relevant to them, which parts are relevant to other players, and what that relevance means for their own future actions and activities. Other games stress visual and binocularity acuity, such as those where dexterity or aiming must come into play. Others do poorly in this category due to component design such as small or heavily ornamented fonts, busy graphical layouts, and a lack of contrast in game boards and game components. Sometimes games incorporate hidden components, hidden hands of card, or otherwise require players to obscure their own personal game state without being able to reveal it to others. This has a considerable impact on how easily a player can request accessibility support through the course of a game. Time constraints too impact on playability in this category, as the investigation of game components with an assistive aid adds a time burden onto every interaction.

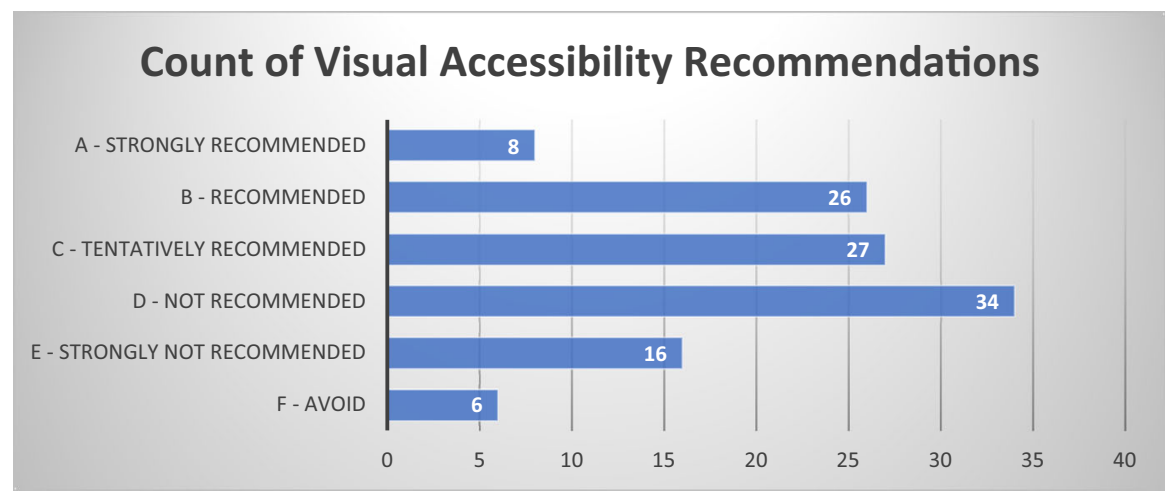

Fig. 3 Recommendation grades for visual accessibility 


\subsection{Fluid Intelligence Accessibility}

Fluid intelligence, according to the rating and numerical weightings outlined above, averages out at a $\mathrm{C}$ - grade. Numerically this comes out as a 7.40 mean with a standard deviation of 3.84 .

As with the grade for visual accessibility, this is skewed upwards because each teardown also considers cognitively accessible variants that could lower complexity and the need to consider and evaluate tactical and strategic implications of actions. As such, games as they are presented in the box are far less accessible than their grades would imply in this category. One of the powerful tools available for accessibility support in this area is the use of house rules. Often a satisfying and enjoyable game can be constructed by changing scoring context or emphasising cooperative rather than competitive play. Figure 4 shows the spread of recommendation grades in this category.

However, even with this taken into account it is still the case that those games that receive the most appreciation on BGG and other sites tend to stress deep thinking and clever interaction of game mechanisms. In most cases these traits are not compatible with the needs of accessibility in this category. Most games incorporate a degree of numeracy, even if only implicitly, and many also require literacy to handle emergent game effects from cards and components. An understanding of probability is core to any game that has a degree of randomness in its systems. Some of the more complex games also emphasise synergy of game mechanisms and rules to ensure that players are able to pull off effects of the greatest impact. The result is that there is a considerable degree of variation in this category, and not often in the most obvious games. Some of the simplest games assessed on Meeple Like Us have also been the most cognitively expensive due to the way the game mechanics cohere. In this category we have many games that we would recommend without concern to any player with cognitive accessibility needs, but more that we'd advise everyone avoid because they are unlikely to be at all playable even with house-rules and modifications.

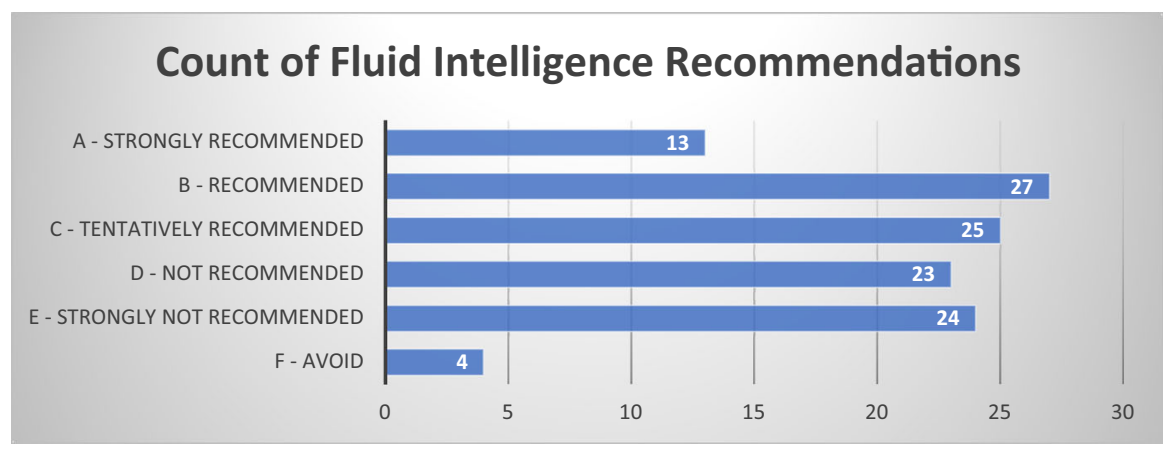

Fig. 4 Recommendation grades for fluid intelligence 


\subsection{Memory Based Accessibility}

Memory based accessibility, according to the rating and numerical weightings outlined above, averages out at a $\mathrm{C}+$ grade. Numerically this comes out as a 8.73 mean with a standard deviation of 3.86 .

Those with memory impairments alone are somewhat better served by modern design because games often provide mechanisms for explicitly tracking game state. However, it is also the case that many games make use of deeper historical knowledge to inform tactical and strategic play. Knowing the composition of a card deck is often important. Remembering complex state-dependant rules and mechanisms can be critical. Some games too stress memory as part of their game mechanisms - either requiring players to explicitly remember instructions they have been given or to track the cards another player has laid down before they eventually come to take effect. Simply remembering rules can be a significant burden in and of itself, and rules-heavy games in particular tend to do poorly in this category. Often the job of a player in a board game is to hold a long term strategy in mind and behave tactically in accordance with that strategy. That needs a relatively sophisticated model of a game to be mentally constructed, and it has to evolve along with changing needs and expectations through the course of play. The spread of recommendations is shown in Fig. 5.

However, even given this the nature of the gameplay models and the potential collegiate support of players at the table makes this category of cognitive accessibility somewhat less problematic than it is for fluid intelligence.

\subsection{Physical Accessibility}

Physical accessibility, according to the rating and numerical weightings outlined above, averages out at a $\mathrm{C}+$ grade. Numerically this comes out as a 9.24 mean with a standard deviation of 3.48 .

The relatively strong performance of board-gaming in this category is derived almost entirely from the fact most games permit a degree of verbalisation even if their physical interactions are likely to be onerous. They permit a player, even one that cannot interact with a board or game state in any meaningful form, to issue instructions for another player to act on their behalf. In conjunction with a card holder, this arrangement permits a very wide variety of games to remain playable and enjoyable because the fundamental enjoyment does not derive from the tactility of the experience. Figure 6 shows the spread of recommendations in this category.

However, this is not universally the case-some games focus on the physicality of interaction. Some games work based on principles of physical dexterity, and others have an interaction model that is real-time and prohibits another player from helping someone else. In such circumstances either the fundamental enjoyability of the experience is lost through verbalisation, or an accessibility compensation becomes something that can only be enacted by someone not actually engaged in the game. It is important to note here that board games are enjoyable, at least in part, because they are something with which you physically interact. There is a lowgrade, persistent satisfaction that comes from manipulating game components in an 


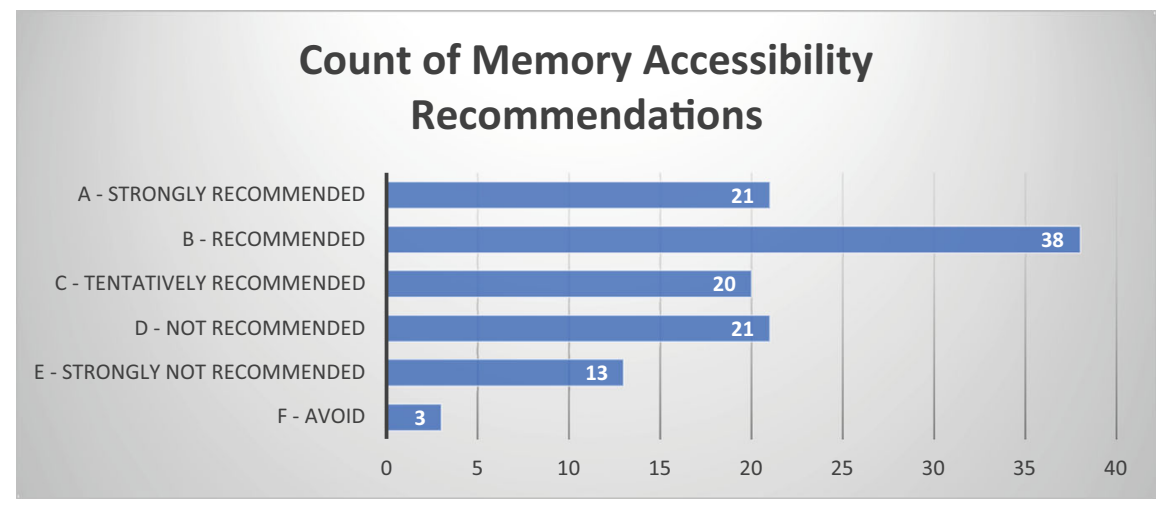

Fig. 5 Recommendation grades for memory

agreeable way. To lose that is not insignificant in any game, but it depends on where the bulk of the fun in a game is to be found as to whether or not we would go on to recommend it in this category.

\subsection{Emotional Accessibility}

Emotional accessibility, according to the rating and numerical weightings outlined above, averages out at a $\mathrm{C}+$ grade. Numerically this comes out as a 9.44 mean with a standard deviation of 3.33 .

To a certain extent, all recommendations in this category must be viewed through a social lens. Even the most emotionally accessible game can be made intolerable by a bad winner or a poor loser. Any game can be a trigger for emotional upset if it's played by people actively out to undermine the fun of others at the table. However, there are also a number of game systems that tend to exacerbate and intensify issues in this category. Some games for example permit players to gang up on another to prevent them winning, or for one player to remove progress from another. Other

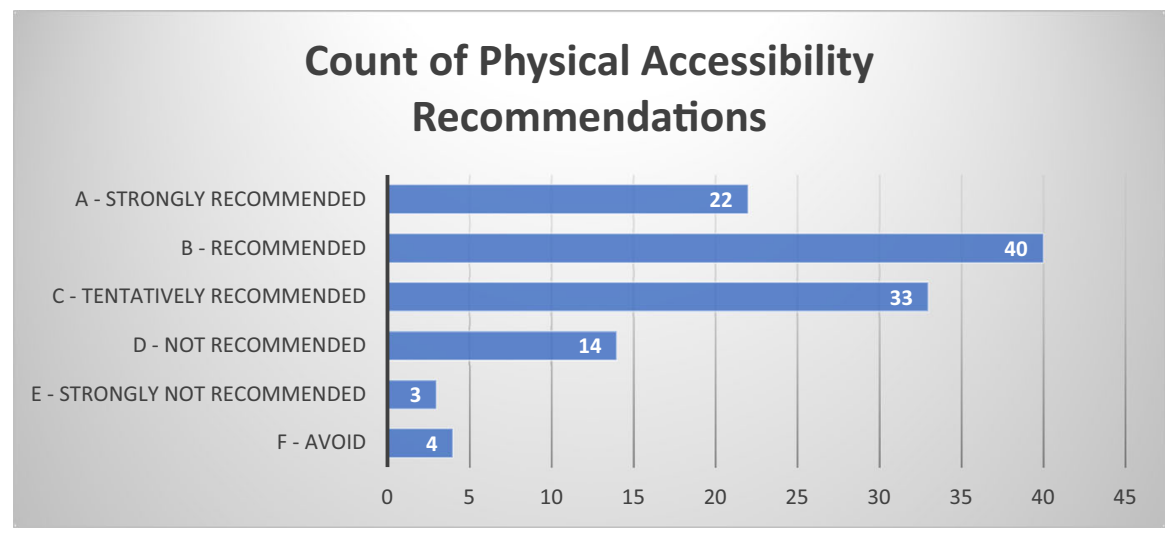

Fig. 6 Recommendation grades for physical accessibility 


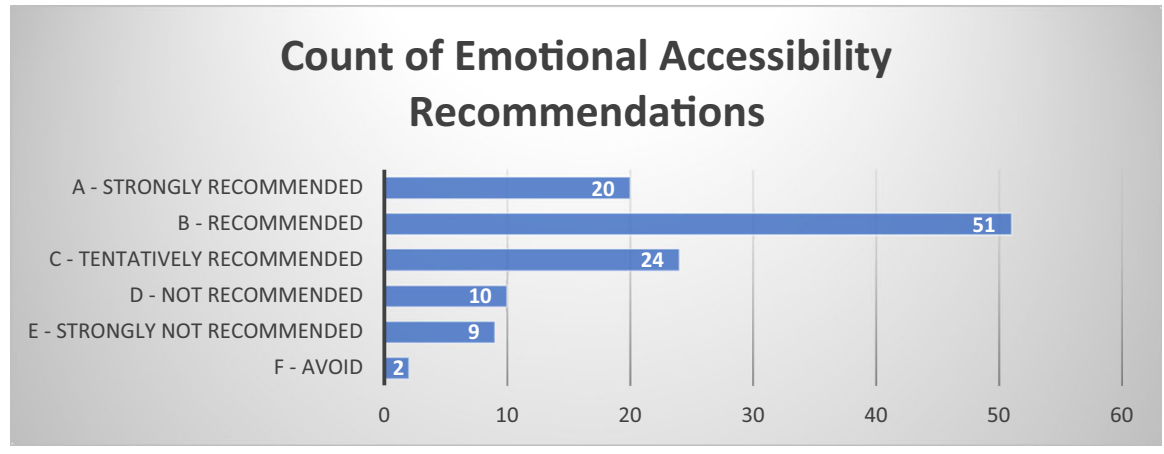

Fig. 7 Recommendation grades for emotional accessibility

games require players to interpret complex social cues or bluff their way through a scenario. Some games, chess being an old-fashioned example, have a sheen of 'intellectualism' about them that adds an additional sting to losing. Other games focus on building patterns but do not necessarily permit those patterns to be completed. All of these issues and more are what end up texturing an accessibility recommendation in this category. Figure 7 shows the distribution of grades.

One feature of modern board-gaming is that many games eschew competition in favour of either a collegiate model of collaboration or a kind of 'fun economy' where people play until they get bored rather than to any conclusion. These in turn add new and interesting factors in this category. Co-operative games as an example ensure that everyone wins or everyone loses, but they also tend to be balanced around a pivot point of intense difficulty to ensure players are challenged. This creates a kind of 'despair curve' where failure is anticipated, expected, or perhaps even inevitable. It takes a certain amount of emotional control to be able to enjoy these kinds of experiences.

The majority of games though retain a degree of competition, and this makes numerous games a problematic fit if issues in this category must be considered. As with the results from the category on fluid intelligence, there is a wide variation in how games here are assessed. Many can be played without any serious concerns, whereas others should be avoided at all costs if a pleasant evening is to be enjoyed by everyone at a table.

\subsection{Socioeconomic Accessibility}

Socioeconomic factors, according to the rating and numerical weightings outlined above, average out at a B. Numerically this comes out as a 10.79 mean with a standard deviation of 3.06 .

A tongue-in-cheek article from a hobbyist board game site ${ }^{7}$ suggested that you were more likely to see a sheep on the cover of a board game than you were a woman. Broadly speaking that is true, and overall board games share a feature with

\footnotetext{
7 http://www.cardboardrepublic.com/articles/extra-pieces/gender-representation-in-board-game-coverart.
} 
video games in that their representation of women is often half-hearted and occasionally regressive (Heron et al. 2014). Issues of representation are important not in terms of the accessibility of play but in terms of the approachability of the culture. In order to see that one is welcome in a hobby, it helps if one can see other 'people like me' participating. In terms of gender balance, board games have improved a considerable amount over the past five or so years. There is a considerable distance left to travel in terms of ethnic representation-most games still present a sea of white faces whenever human figures are shown. Figure 8 shows the distribution of recommendations in this category.

With that in mind it might be strange to see the grade skews so high. Partially this is because many games have no art at all that might be considered representative of humans. A large number of games are abstract, having no strict theme they attempt to express through aesthetics. Many games use art that is thematic but does not contain any people - spaceships and castles and dark forests. Other games make a special effort to address the representational barrier, doing an excellent job of including a range of ethnicities and genders, even occasionally non-binary. These raise the recommendations upwards even as others drag it down somewhat. There are though still many games with overtly sexualised art, demeaning portrayals of women and minorities, and that are homophobic or transphobic in language and mechanisms. Many of those do not fall within the remit of Meeple Like Us, but they are still out there.

Also complicating an aggregate rating in this category is the fact that cost is explicitly linked into the sociological context. This is important because there is a tight relationship between financial constraints and ethnic background (Goodley 2016; Dawson 2014) in many circumstances. Socioeconomic factors inform and shape each other, and as such the two are inextricably linked in a real-world context. However, this does mean that it is somewhat difficult to unpick the contributory factors in the flattened statistical analysis shown above. A cheap game with poor representation will be lifted upwards as a consequence of the conflation. Individual accessibility teardowns are more precise in this regard.

Germane to this discussion are issues of cost and associated business models. Some games operate on a collectible model, where 'booster' packs give randomised access to common, unusual and rare game components. Such game stress an ongoing an escalating financial commitment where a player may invest considerable money without ever getting the specific thing they were seeking. Other games are presented as 'core sets' which give an initial sampling of the game but are only a down-payment on a cycle of expansions and supplements that are necessary to enjoy the full experience. Other games are offered as a single, complete product with no expectation of ongoing cost. Some games offload issues of representation into expansions, essentially creating the circumstance where baseline diversity is only available through ongoing purchases of extra material.

Some of these business models are difficult to describe as anything other than exploitative, but they are still relatively rare in an environment where expansions are optional, rather than expected, additions to a game experience. As such, at the current time, this is a hobby that is relatively well served in this category because 


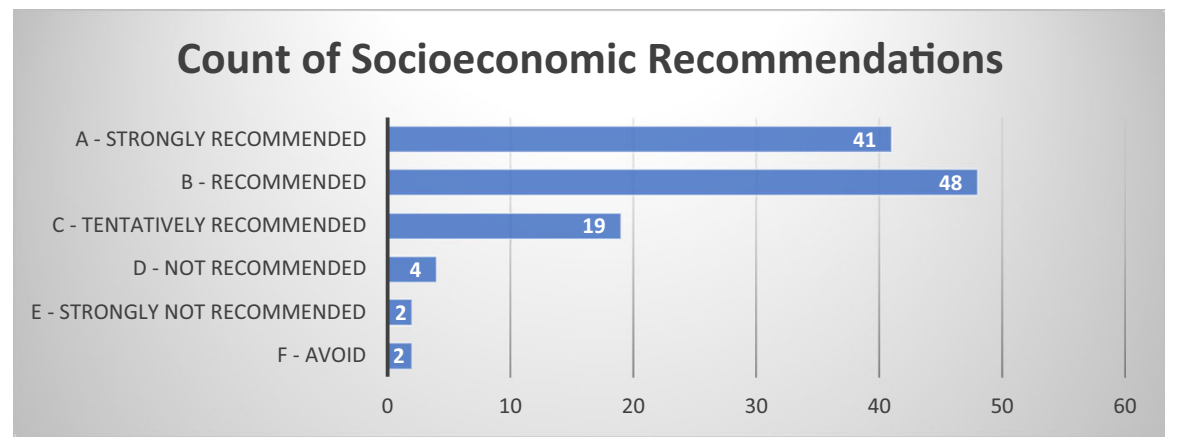

Fig. 8 Recommendation grades for socioeconomic accessibility

explicit transgressions in terms of representation and cost remain relatively unusual within the scope of this particular project.

\subsection{Communicative Accessibility}

Communicative factors, according to the rating and numerical weightings outlined above, averages out at a $\mathrm{B}+$. Numerically this comes out as a 11.47 mean with a standard deviation of 2.89 .

Specific need for communication remains relatively rare in games-table talk is an important part of most social gameplay, but it's only rarely an actual game mechanism that must be navigated and mastered. There are games that work on this basis, but by and large if someone is reasonably literate games rarely present significant barriers in this category. For those for whom literacy may be an issue, there are many games that make use of abstract symbology alone to convey important game state and mechanisms. Figure 9 shows the distribution of recommendation grades in this category.

There are though occasionally games that stress communication under difficult circumstances, or within time constraints, or where the sophistication of communication is such that it places a supererogatory burden on both expression and interpretation of speech. Such games tend to explicitly focus on this rather than have it as an unintended by-product and we must accept here that sometimes the fun in a game comes from its explicit inaccessibility. If a game is about bluffing your way past your friends and trying to convince people that others are lying, it is only to be expected that communicative faculties might be stressed beyond the feasible limits of accessibility. By and large though this is a category where the prime unit of concern is the individual title rather than the hobby as a whole. 


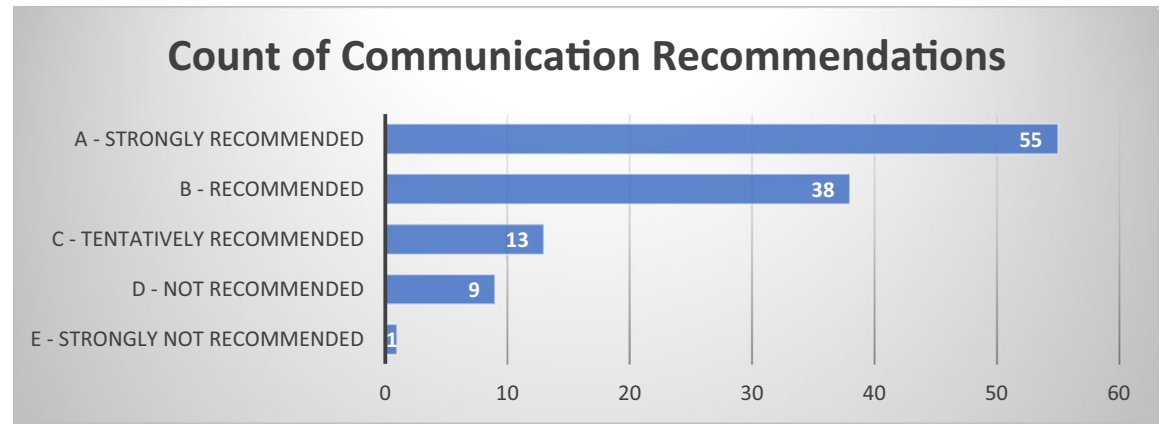

Fig. 9 Recommendation grades for communication

\section{Future Work}

What this work has discovered to date is that there is an awful lot of variety out there in this gaming space. Every game discussed so far on Meeple Like Us has had at least one unique feature about it that made it entirely distinctive and meritorious of discussion. As such, while this work has been ongoing for eighteen months it's fair to say there is still a considerable distance to go before the supply of accessibility novelty dries up.

However, enough of the accessibility landscape has been covered now to begin distilling these observations down into actionable guidance for tabletop game developers. To that end, the next phase of this project will include the development of a set of Tabletop Accessibility Guidelines (TTAG) which will parallel the development and dissemination of the Game Accessibility Guidelines. ${ }^{8}$ The intention is for this to serve as a quick reference for those looking to expand their audience through accessible game design. The work of Meeple Like Us has discovered numerous candidate guidelines that would be appropriate for this. A working group to develop these has been assembled comprised of accessibility researchers, people with disabilities, game publishers, game designers, and game manufacturers. Currently the project has put together a list of hundreds of accessibility guidelines. The next stage of the work is to look for opportunities to combine, clarify and amplify these. The end result will be a small set of easily digested guidance notes that will result in real, meaningful improvements in tabletop game accessibility. Important to this work is that each guideline will be validated according to several deliverable principles:

1. Is it useful to those with accessibility considerations?

2. Is it feasible to include for game designers?

3. Is it possible to support for game publishers?

4. Is it economical to produce for game manufacturers?

\footnotetext{
${ }^{8}$ http://gameaccessibilityguidelines.com/.
} 
Guidelines will be offered in terms of their impact and also the extent to which they answer yes to each of these key considerations. The intention is to offer a sliding scale of accessibility that goes from the simplest fixes all the way to the aspirational. Given the per unit implication discussed above, it is not simply the case that we can necessarily argue that accessibility makes money. Here, the cost is not necessarily borne upfront-it is borne with every unit produced, every unit stored, and every unit distributed and shipped. It is difficult to argue accessibility is necessary for the financial wellbeing of the industry when the cost of providing it could potentially be greater than the additional revenues derived from expanding audience share. Advocacy for accessibility within this space must be tempered with pragmatism.

Alongside this, the work of assessing the accessibility landscape of tabletop gaming will continue-it remains the intention of the project to develop and publish an accessibility teardown of a new game every week, and with each of those games to further inform the work being done on the TTAG initiative. Important to the goals of TTAG is that impacted stakeholders have a library of exemplars of each guideline to which they can refer. The existing data set of Meeple Like Us serves as a fertile ground for that, but it is vital that all derived guidelines can be linked to an existing example of best and worst practice. This will permit designers and publishers to see how their choices interact in a real-world context. Ensuring this is always possible is done through continually exploring the accessibility profiles of new games and presenting those conclusions to the hobbyist gaming audience for consideration.

\section{Conclusion}

The work of Meeple Like Us is problematic in many ways. It is, of a necessity, based on informed heuristics rather than embodied experience. It cannot keep up with the publication schedule of new games, and has not yet managed to cover an appreciable fraction of the games that have been released in the past twenty years. BoardgameGeek (BGG) currently has around 95,000 games stored in its databases. Meeple Like Us has covered one hundred and sixteen of those. Every week, the project falls father behind.

For this reason, the scope of the project is somewhat more realistic-to cover an appreciable fraction of the BGG Top 500 in terms of how they present themselves as accessible products. The recommendations derived from this work are subjective, have not been validated against any reliable or quantifiable source, and reflect the inherent biases of the methodology. However, it is not to say that the work thus has no merit-given the nature of the challenge the choice is between a limited investigation of the accessibility landscape and no investigation at all. It is not that these methodological issues are mistakes-they are fundamental limitations of the inquiry.

Choosing the impossibility of perfection would be a tremendous missed opportunity. The current accessibility landscape for tabletop games is full of fascinating accessibility challenges and interaction nuances. As hobbyist games 
continue to grow in popularity and profile, it's important that they are held to the same standards which we apply to other forms of recreation. Historically, accessibility has not been a priority of board game designers and publishers. The work of Meeple Like Us, supported as it is by a reasonably large and reliable audience, is helping raise the profile of this issue. The work has already led to numerous useful collaborations with publishers and designers. By ensuring a regular dissemination of this information it has also brought together an informal group of gamers with disabilities who can reflect upon and inform the recommendations made on the site. It is important to note here that part of the solution to the methodological problems of Meeple Like Us lie in the teardown philosophies. A teardown doesn't represent the end of a conversation-it's the start of one.

\section{Compliance with Ethical Standards}

Conflict of interest On behalf of all authors, the corresponding author states that there is no conflict of interest.

Open Access This article is distributed under the terms of the Creative Commons Attribution 4.0 International License (http://creativecommons.org/licenses/by/4.0/), which permits unrestricted use, distribution, and reproduction in any medium, provided you give appropriate credit to the original author(s) and the source, provide a link to the Creative Commons license, and indicate if changes were made.

\section{References}

Barbara, J. (2017). Measuring user experience in multiplayer board games. Games and Culture, 12(7-8), 623-649.

Bremer, P. (2017). Games people play. The Reference Librarian, 58(3), 202-205.

Cattell, R. B. (1963). Theory of fluid and crystallized intelligence: A critical experiment. Journal of Educational Psychology, 54(1), 1.

Crist, W., Voogt, A., \& Dunn-Vaturi, A. E. (2016). Facilitating interaction: Board games as social lubricants in the Ancient Near East. Oxford Journal of Archaeology, 35(2), 179-196.

Dawson, E. (2014). "Not designed for us": How science museums and science centers socially exclude low-income minority ethnic groups. Science Education, 98(6), 981-1008.

Few, S. (2005). Keep radar graphs below the radar-far below. Information Management, 15(5), 48.

Goodley, D. (2016). Disability studies: An interdisciplinary introduction. London: Sage.

Gotay, S. (2013). Enhancing emotional awareness of at-risk youth through game play. Journal of Creativity in Mental Health, 8(2), 151-161.

Gregor, P., Newell, A. F., \& Zajicek, M. (2002). Designing for dynamic diversity: Interfaces for older people. In Proceedings of the fifth international ACM conference on assistive technologies (pp. 151-156). ACM.

Guhe, M., \& Lascarides, A. (2014). Game strategies for the settlers of Catan. In Computational intelligence and games (CIG), 2014 IEEE conference on (pp. 1-8). IEEE.

Hall, M. A. (2016). Board games in boat burials: Play in the performance of migration and viking age mortuary practice. European Journal of Archaeology, 19(3), 439-455.

Heron, M. (2012). Inaccessible through oversight: The need for inclusive game design. The Computer Games Journal, 1(1), 29-38.

Heron, M. J. (2015). A case study into the accessibility of text-parser based interaction. In Proceedings of the 7th ACM SIGCHI symposium on engineering interactive computing systems (pp. 74-83). ACM.

Heron, M. J. (2016). Cultural integration and the accessibility of gaming. The Computer Games Journal, 5(3), 91-94. (Springer: New York).

Heron, M. J., Belford, P., \& Goker, A. (2014). Sexism in the circuitry: Female participation in maledominated popular computer culture. ACM SIGCAS Computers and Society, 44(4), 18-29. 
Heron, M., Hanson, V. L., \& Ricketts, I. W. (2013a). Accessibility support for older adults with the ACCESS framework. International Journal of Human-Computer Interaction, 29(11), 702-716.

Heron, M., Hanson, V. L., \& Ricketts, I. W. (2013b). ACCESS: A technical framework for adaptive accessibility support. In Proceedings of the 5th ACM SIGCHI symposium on engineering interactive computing systems (pp. 33-42). ACM.

Imrie, R. (2004). Disability, embodiment and the meaning of the home. Housing Studies, 19(5), 745-763.

Karimi, H. A., Zhang, L., \& Benner, J. G. (2014). Personalized accessibility map (PAM): A novel assisted wayfinding approach for people with disabilities. Annals of GIS, 20(2), 99-108.

Katzenbach, C., Herweg, S., \& Van Roessel, L. (2016). Copies, clones, and genre building: Discourses on imitation and innovation in digital games. International Journal of Communication, 10, 22.

Kwan, M. P. (2013). Beyond space (as we knew it): Toward temporally integrated geographies of segregation, health, and accessibility: Space-time integration in geography and GIScience. Annals of the Association of American Geographers, 103(5), 1078-1086.

Matorin, A. I., \& McNamara, J. R. (1996). Using board games in therapy with children. International Journal of Play Therapy, 5(2), 3.

McCormick, K., Anderberg, S., Coenen, L., \& Neij, L. (2013). Advancing sustainable urban transformation. Journal of Cleaner Production, 50, 1-11.

Milne, S., Dickinson, A., Carmichael, A., Sloan, D., Eisma, R., \& Gregor, P. (2005). Are guidelines enough? An introduction to designing web sites accessible to older people. IBM Systems Journal, 44(3), 557-571.

Newell, A. F., \& Gregor, P. (2000). "User sensitive inclusive design"-in search of a new paradigm. In Proceedings on the 2000 conference on universal usability (pp. 39-44). ACM.

Newell, A. F., Gregor, P., Morgan, M., Pullin, G., \& Macaulay, C. (2011). User-sensitive inclusive design. Universal Access in the Information Society, 10(3), 235-243.

Noble, K., \& Crabb, M. (2016). Projection mapping as a method to improve board game accessibility. ACM SIGACCESS Accessibility and Computing, 116, 3-9.

Porter, J. R., \& Kientz, J. A. (2013). An empirical study of issues and barriers to mainstream video game accessibility. In Proceedings of the 15th international ACM SIGACCESS conference on computers and accessibility (p. 3). ACM.

Pullin, G., \& Newell, A. (2007). Focussing on extra-ordinary users. In Universal access in human computer interaction. Coping with diversity (pp. 253-262).

Rode, P., Floater, G., Thomopoulos, N., Docherty, J., Schwinger, P., Mahendra, A., \& Fang, W. (2017). Accessibility in cities: Transport and urban form. In Disrupting mobility (pp. 239-273). Springer International Publishing.

Rogerson, M. J., Gibbs, M., \& Smith, W. (2016). I love all the bits: The materiality of boardgames. In Proceedings of the 2016 CHI conference on human factors in computing systems (pp. 3956-3969). ACM.

Szita, I., Chaslot, G., \& Spronck, P. (2009). Monte-Carlo tree search in settlers of catan. ACG, 6048, 21-32.

Taylor, D. P. (2014). Investigating approaches to AI for trust-based, multi-agent board games with imperfect information; with Don Eskridge's "the resistance". Discovery, Invention \& Application. https://computing.derby.ac.uk/ojs/index.php/da/article/view/68. Accessed 20 Apr 2018. 